\title{
La influencia del método de Ahn en España en los siglos XIX y XX a través de una mirada a la prensa histórica
}

Alberto Lombardero Caparrós

\section{(2) OpenEdition \\ Journals}

\section{Edición electrónica}

URL: https://journals.openedition.org/dhfles/4453

DOI: $10.4000 /$ dhfles.4453

ISSN: 2221-4038

Editor

Société Internationale pour l'Histoire du Français Langue Étrangère ou Seconde

Edición impresa

Fecha de publicación: 1 diciembre 2017

Paginación: 83-101

ISSN: 0992-7654

Referencia electrónica

Alberto Lombardero Caparrós, «La influencia del método de Ahn en España en los siglos XIX y XX a través de una mirada a la prensa histórica », Documents pour I'histoire du français langue étrangère ou seconde [En ligne], 58-59 | 2017, mis en ligne le 04 juin 2018, consulté le 26 mars 2023. URL : http:// journals.openedition.org/dhfles/4453; DOI : https://doi.org/10.4000/dhfles.4453

Este documento fue generado automáticamente el 26 marzo 2023.

Tous droits réservés 


\title{
La influencia del método de Ahn en España en los siglos XIX y XX a través de una mirada a la prensa histórica
}

\author{
Alberto Lombardero Caparrós
}

\section{Introducción}

1 El profesor y pedagogo alemán Johann Franz Ahn (1797-1865) innovó y triunfó en el ámbito de la enseñanza de idiomas con la publicación de su Praktischer Lehrgang zur schnellen und leichten Erlennung der Französischen Sprache (1834). Dicho éxito está avalado por el inusual número de ediciones que cosechó su primer curso de francés, unas 221 en el siglo XIX, llegando hasta la edición número 237 en 1921. En 1840 Ahn publica su segundo curso de francés al que le seguirían, en años posteriores, obras similares en los idiomas Inglés, Italiano, Alemán, Holandés, Griego moderno y Ruso. Ninguno de estos manuales conseguiría un éxito tan rotundo como su primer curso de francés.

2 A diferencia de Ahn, que nunca utilizó la palabra 'método' en sus manuales, sus adaptadores europeos, primero, y americanos, después, si la incluyeron en los títulos de sus manuales (ver apéndice).

España no quedó al margen de la influencia de Franz Ahn. Los autores que incluyeron el título genérico de 'Método de Ahn' en el título de sus manuales para aprender diversas lenguas extranjeras en España fueron, por orden de aparición, Henry Mac Veigh para los cursos de francés ( $1^{\mathrm{a}}$ ed. 1857) e inglés ( $1^{\mathrm{a}}$ ed. 1859) ; Camilo Vallés para el alemán ( $1^{\mathrm{a}}$ ed. 1873) ; Francisco María Rivero para el italiano (1 $1^{\mathrm{a}}$ ed. 1873) y Paula Hidalgo para el portugués ( $1^{\mathrm{a}}$ ed. 1876). Salvo la primera edición del curso de francés e inglés, todas las restantes fueron publicadas por la editorial Bailly-Baillière fundada en 1848 en Madrid por Carlos Bailly-Baillière. 


\section{La prensa histórica ${ }^{1}$}

4 Nuestra investigación se ciñe a la consulta de dos hemerotecas digitales de prensa histórica, la HDBNE y la $\mathrm{BVPH}^{2}$. En ambos catálogos se utilizaron los mismos parámetros de búsqueda : para la entrada de búsqueda se usó la expresión 'Método de Ahn' y para el período temporal se escogió entre el 1 de enero de 1850 y el 31 de diciembre de 1950. El primer parámetro coincide con el epígrafe que aparece en la parte superior central de todos los manuales de los adaptadores de Ahn en España. El segundo amplía el período en sus dos extremos para obtener una mayor visión histórica de la influencia de Franz Ahn. En realidad, el período queda acotado entre 1857 y 1937 si nos atenemos a los resultados de la primera y última referencia al 'Método de Ahn' encontradas en sendas hemerotecas.

5 El número de resultados fue de 608 en la HDBNE y de 437 en la BVPH. Del millar de resultados en total, alrededor de un tercio de ellos no arrojó ninguna información relevante a nuestra búsqueda mientras que el restante setenta por ciento representa la constatación de una significativa presencia del 'Método de Ahn' en la prensa histórica española. Estos resultados pueden clasificarse en cuatro tipos (organizados de mayor a menor aparición) :

Anuncios de los diferentes manuales editados en la prensa española.

Anuncios de clases privadas en Academias donde se enseñaba según el método de Ahn.

8 Extractos de prensa en forma de artículos, recomendaciones bibliográficas, cartas al director.

La entrada de la expresión 'Método de Ahn' en la cultura popular con tintes de parodia.

\subsection{Anuncios de manuales}

El primer anuncio encontrado data de 1857 y aparece en la página tres del Diario Oficial de Avisos de Madrid fechado un 28 de octubre. En él se anuncia la publicación de un manual titulado Tratado elemental para aprender el francés, compuesto por el profesor H. M. Veigh, con arreglo al METODO NATURAL Y ATRACTIVO DEL DOCTOR AHN. No se menciona qué edición es pero creemos que se trata de la primera por el hecho que no se han encontrado anuncios anteriores a 1857. El anuncio acaba mencionando el precio y los diversos puntos de venta: Véndese a 8 rs. En rústica y 10 encuadernado á la inglesa en las librerías de Bailly Bailliere, Duran, Cuesta y Villaverde y en casa del autor ACADEMIA DE LENGUA INGLESA, calle de la Salud, núm. 8 principal. Este anuncio vuelve a aparecer en el mismo diario el 2 de noviembre y en tres periódicos más: en La Época el 2 de noviembre; en El Clamor Público y en La Discusión un 6 de noviembre. Dos meses más tarde, un 26 de enero de 1858, aparece en el Diario Oficial de Avisos de Madrid un nuevo anuncio de un manual para aprender francés titulado EL PRIMER CURSO DE FRANCÉS, con arreglo al método atractivo y sencillísimo del doctor Ahn, escrito por H. Mac Veigh. De nuevo no aparecen ni el número de edición ni el editor, sólo el precio y los puntos de venta. Este mismo anuncio vuelve a aparecer en otro periódico llamado La Esperanza los días 18 y 25 de febrero. En el mismo rotativo aparece un nuevo anuncio, fechado los días 26 y 29 de junio del mismo año, anunciando la aparición de la primera edición de El Segundo curso de francés, escrito por Henry Mac-Veigh. Tres meses más tarde, en el 4 y 5 de septiembre, aparece en La Iberia un anuncio en el que se oferta El primero y segundo curso 
de francés, con arreglo al método sencillo y natural del Dr. Ahn junto a la Clave de temas de ambos cursos, por separado. Este anuncio es el único de todos los encontrados que incluye una sección, bastante larga, llamada 'Extractos de Opinión' y que recoge diversos comentarios muy favorables al método de Ahn de diversos periódicos.

En 1859 el espectro de lenguas se amplía al inglés como así lo confirma un anuncio aparecido en el Diario Oficial de Anuncios de Madrid (ejemplares del 3, 4 y 5 de octubre). El escueto título de la obra, Método de Ahn. Primer curso de inglés, será homogéneo a partir de entonces para todos los manuales, sobre todo a partir de 1862 cuando la casa editorial madrileña Bailly-Baillière adquiere los derechos de la obra de Ahn en España. A partir de 1862, todos los anuncios de manuales según el método de Ahn correrán a cargo de la empresa editorial Bailly-Baillière, regentada por Carlos Bailly-Baillière. Así lo atestigua la aparición de un mismo anuncio en cuatro diarios de la época ( $L a$ Época, La Discusión y La Iberia entre el 25 de septiembre y el 4 de octubre y en El Monitor de la Salud el 15 de diciembre de 1862).

La presencia de anuncios en la prensa aumenta exponencialmente tal como avanza el siglo XIX. La campaña editorial da sus frutos y en pocos años el número de ediciones va en aumento, sobre todo las del idioma francés. Un ejemplo de ello lo pone de manifiesto un anuncio aparecido al unísono en La Esperanza, La Regeneración, La Época, el Diario Oficial de Avisos de Madrid, La España y en El Pensamiento Español entre el cinco y el dieciocho de septiembre de 1866. En dichos diarios se anuncia la salida de la sexta edición del Método de Ahn. Primer curso de francés acompañado de un texto promocional de la editorial Bailly-Baillière, en el cual se puede leer :

El Método de Ahn para aprender la lengua francesa está reconocido en toda Europa por el más sencillo y el más adecuado á la enseñanza (puede decirse que es el método de ollendorff simplificado); así es que hoy se halla adoptado en casi todos los establecimientos.

La mención al 'método de Ollendorff', muy popular también en la época, puede interpretarse como una estrategia editorial, especialmente en una década, la del 60 del siglo XIX en que se publicaron más de una treintena de nuevos manuales para aprender francés (Fischer et al. $2004:$ 247-249).

década de los 70 del siglo XIX testimonió una creciente presencia de anuncios en la prensa con nuevos manuales y nuevas ediciones que se añadían a los ya publicados anteriormente por Bailly-Baillière. Un ejemplo de ello aparece en el Diario Oficial de Avisos de Madrid del 1 y 2 de octubre de 1874 y repetido en La Igualdad, La Iberia, La Época, y El imparcial entre el 2 y el 21 de octubre de ese mismo año. En vez de concentrar la atención en un solo idioma, este anuncio, como ya será habitual, incluye las diferentes ediciones nuevas del método de Ahn para el francés y el inglés con la novedosa aparición de un primer y segundo curso de italiano :

Método de Ahn. Primer curso de francés. 13ª ed. 1874

16 Segundo curso de francés con clave. $7^{\mathrm{a}}$ ed. 1874

17 Curso de Inglés. $3^{\text {a }}$ ed. 1873

18 Clave de temas del curso de inglés. $3^{a}$ ed. 1873

19 Primer y segundo curso de italiano. 1873

20 En el mismo anuncio aparece una nota escrita por la editorial en la que se subraya la popularidad del método de Ahn, por ser de todos conocido como el más sencillo y práctico de todos los demás publicados. 

método de Ahn haciendo referencia a su universalidad: Los métodos de Ahn, universalmente reconocidos como los más sencillos para aprender un idioma con facilidad y en universalmente reconocidos como los más sencillos para aprender un idioma con facilidad y en
poco tiempo, están adoptados de texto en el mundo entero por todos los establecimientos de enseñanza.

42

Sin lugar a dudas, la popularidad del método de Ahn iba in crescendo de la mano de una de las casas editoriales más importantes de España en aquel tiempo aunque, por cuestiones de espacio, no podemos hacernos eco del ingente número de anuncios encontrados entre las décadas de los 70 y 80 del siglo XIX. No obstante, hemos seleccionado un anuncio de finales de la década de los 80 para dejar constancia del impacto que causaba el método de Ahn en la sociedad española. El anuncio en cuestión apareció en el Anuario del comercio, de la industria, de la magistratura y de la administración en 1888. Ocupa casi una página convirtiéndose en uno de los de mayor tamaño de todos los consultados, siendo un claro ejemplo de la exitosa producción editorial de manuales basados en el método de Ahn. En resumen, el contenido es el siguiente :

Primer curso de francés. $30^{\mathrm{a}} \mathrm{ed}$.

Segundo curso de francés. $20^{\mathrm{a}}$ ed.

Clave de los temas del primer y segundo curso de francés. $17^{\mathrm{a}} \mathrm{ed}$.

Primer libro de traducción del francés. 1885

Primer curso de alemán. $3^{\text {a }}$ ed.,1888

Segundo curso de alemán. $3^{\mathrm{a}}$ ed., 1888

Tercer curso de alemán. $2^{\text {a }}$ ed. 1888

Clave de los tres cursos de alemán. $2^{a}$ ed. 1888

Curso de inglés. $10^{\mathrm{a}}$ ed. 1888

Clave de los temas del curso de inglés. $7^{\text {a }}$ ed. 1888

Primer curso de italiano. $5^{\mathrm{a}}$ ed., 1887

Segundo curso de italiano. $5^{\mathrm{a}}$ ed., 1887

Primer y segundo curso de portugués. 1876

El último anuncio que incluye el número de ediciones de los manuales del método de Ahn lo encontramos en El Heraldo de Madrid publicado el 3 y 5 de octubre respectivamente del año 1892. Esta vez, sólo incluye los idiomas francés e inglés y, aunque sólo lo separan cuatro años del anuncio anteriormente expuesto, sorprende ver el gran éxito de ventas que supusieron los cursos de francés e inglés tal como demuestran las diferentes ediciones anunciadas :

Primer curso de francés. $36^{\mathrm{a}}$ ed., 1891

Segundo curso de francés. $31^{\mathrm{a}}$ ed., 1892

Clave francés. $24^{\mathrm{a}}$ ed., 1892

Curso de inglés. $13^{\mathrm{a}}$ ed., 1891

Clave inglés. $14^{\mathrm{a}} \mathrm{ed} .1892$

Así mismo, al final de este mismo anuncio aparece un texto promocional sobre el

El último anuncio encontrado relativo al período entre 1850 y 1950 data del 5 de octubre de 1894. Sólo se encontró en un diario, El Imparcial, y su diseño no se repite en 
ningún otro anuncio previo ni posterior. Finalmente, la singularidad de este anuncio se hace también palpable por el hecho de ir dirigido tanto a profesores como a alumnos :

ENSEÑAD Y APRENDED por el metodo Sencillo de AHN de texto en todos los colegios :

El Francés

El Alemán

El Inglés

El Italiano

El Portugués

De venta en la librería de Bailly-Baillièreé Hijos, Madrid, y en todas las librerías y centros de suscrición de España y Ultramar.

\subsection{Anuncios de clases privadas}

Otro indicador de la implantación del método de Ahn en territorio español está constituido por un subtipo de anuncios como son las clases privadas o particulares de idiomas en la España de aquel período.

En total nuestra búsqueda arrojó cinco resultados que incluimos a continuación. El primero de ellos apareció en el Diario Oficial de Avisos de Madrid el 9 de mayo de 1862. Se trata de un anuncio anónimo en el que se ofrecen clases de inglés y de español para extranjeros. Otro hecho singular sobre este anuncio es que está incluido en una sección del periódico llamada Sección Científica cuya única entrada la constituye el anuncio en cuestión : Lecciones de inglés, por el $^{3}$ breve método de Ahn. Calle de Pontejos, núm. 10, cuarto cuarto derecha. Se enseña el español á los estranjeros.

2 El segundo anuncio desvela, por casualidad, quién era el profesor anónimo del primer anuncio como veremos a continuación. Se trata de un anuncio con una doble finalidad: ofrecer clases privadas de inglés y francés e incluir algunos manuales escritos por el mismo profesor. Este anuncio resulta ser muy significativo desde un punto de vista historiográfico por evidenciar que algunos autores de manuales para la enseñanza de idiomas también trabajaron como profesores de idiomas privados probablemente debido a que los emolumentos que recibían de las editoriales para las que trabajaban eran bastante exiguos. El anuncio en cuestión es el siguiente :

EL PROFESOR DE INGLES H. MAC VEIGH, dá principio á sus clases desde hoy. 㡠 Calle de

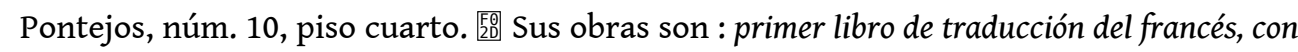
notas y vocabulario ; su precio, 7 reales : muy recomendable como obra elemental.

Primer curso de inglés (método de Ahn), á 10 rs. 跴 Clave, 4 rs.

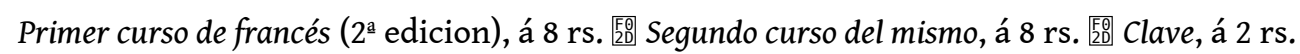

British Class Book ó Lecciones de literatura inglesa, sacadas de los mejores prosistas y poetas, con una reseña gramatical y vocabulario. Precio, 30 reales. Se hallan de venta en las principales librerías de Madrid.

Pocos días después de la fecha del anterior anuncio aparece otro anónimo en La Correspondencia de España del 7 de octubre de 1862, donde una academia privada ofrece clases de francés siguiendo el método de Ahn: ACADEMIA DE FRANCÉS, POR EL breve y sencillo método de Ahn. Montera, 40, segundo. Lecciones particulares.

Documents pour l'histoire du français langue étrangère ou seconde, 58-59 | 2017 

publicación, Revista Contemporánea, con dieciséis años de diferencia. El primero de ellos data de 1888 y lleva por título Método que debiera emplearse en la enseñanza de las lenguas vivas señaladamente del alemán. Fue escrito por Cándido Ríos y Rial, Catedrático de Historia natural en el Instituto de segunda enseñanza de Guipúzcoa. En su artículo, Ríos (1888: 261) se refiere a los métodos de ollendorff y de Ahn como unos 'métodos que revisten cierta originalidad' por ser 'adaptables á diversas lenguas imprimiéndoles más o menos 
novedad' y por producir unas 'gramáticas que acostumbran á dividir en dos partes: una práctica y otra teórica, en la cual se trata el idioma bajo el punto de vista filológico.

El segundo artículo, aparecido en 1904 también en la Revista Contemporánea, es la transcripción del Discurso inaugural del Centro Asturiano hecho por el académico, escritor y periodista Antonio Balbín de Unquera (1842-1919). Lleva por título Enseñanza de las lenguas vivas y principalmente de la lengua inglesa. En él su autor hace una referencia implícita a los métodos prácticos de Ahn y Ollendorff, entre otros, poniendo de relieve su importancia en un pasado pero que entonces, a inicios del siglo XX, ya habían perdido su vigor ante la aparición de nuevos métodos. Según Balbín (1904 : 265), Los métodos prácticos de composiciones y de temas y de claves tienen su razón de ser, y que ha debido mirarse como un progreso, pero únicamente cuando se trate de aprender las lenguas extranjeras en cualquier concepto que no sea el literario.

Balbín, pues, acepta los métodos prácticos como válidos para la enseñanza de lenguas extranjeras aunque personalmente se considera partidario de un método ecléctico que define así :

... nosotros respecto al método de enseñar las lenguas extranjeras somos eclécticos ; para los propósitos literarios no vemos otro mejor que el teórico y gramatical antiguo; para los fines prácticos de la conversación, escritura sin pretensiones literarias y comunicación, consideramos admisibles los métodos prácticos. Aún así, entendemos que debe descargarse, en gracia de la utilidad, el método teórico gramatical de muchos pormenores... y que los métodos prácticos deben tomar una forma algo más científica, si queremos que los alumnos se den cuenta de lo que son $\mathrm{y}$ valen los idiomas que estudian.

71 Nuestro siguiente documento histórico nos devuelve a finales del siglo XIX cuando la influencia del método de Ahn aún era palpable como lo demuestra una carta escrita en la sección de Cartas al Director aparecida en El Correo Militar un 5 de marzo de 1895. Fue escrita por A. U. (no se dan más señas) y llevaba por título Más sobre Segunda Enseñanza. $\mathrm{Su}$ autor anónimo contrapone la enseñanza de idiomas en los institutos de segunda enseñanza con la de la Escuela Superior de Guerra y no duda en recomendar el método de Ahn, utilizado en la segunda, para mejorar el aprendizaje de lenguas en los institutos :

[...] En la Escuela Superior de Guerra, en que amplían sus estudios los oficiales más brillantes de nuestro ejército, conténtase el ilustradísimo profesor de francés con el sencillo método de Ahn y obtiene grandes resultados; en cambio los textos que obligan á estudiar á los futuros bachilleres, son de extensión y dificultad tal, que embarullando al alumno, se consigue que en dos cursos completos tan sólo aprenda á mal leer ; pero en compensación, cuesta el método de Ahn cinco pesetas y quince el que se da en los institutos, y váyase lo uno por lo otro.

72 Ya vimos anteriormente cómo el método de Ahn compartía protagonismo con otros métodos a partir de finales del siglo XIX, extremo también confirmado por esta carta al director. Ésta será la tónica durante las primeras décadas del siglo XX como muestra el último extracto de prensa hallado en la sección de recomendaciones bibliográficas.

La Unión Ilustrada del 28 de abril de 1929 dedica la página cuarenta y dos a dar información bibliográfica sobre diversas gramáticas y métodos para aprender idiomas. Observamos cómo la oferta editorial de manuales para la enseñanza de idiomas ha crecido extensamente. De hecho, ya no se mencionan los métodos de Ahn para el francés e inglés y tan sólo se recomiendan para el italiano, el alemán y el portugués. Por ejemplo, para el francés existen otros métodos como los de Henry Meyer, T. Grübert, 
René H. Thierry, José Meca Tudela y Luis Besses y para el idioma inglés los métodos de Lewis Girau, José Garrón Ruiz, José Casadesús y R. Seaber.

Ciertamente, la amplia oferta de manuales para aprender francés e inglés a finales del primer tercio del siglo XX relegó al olvido los métodos de Ahn, al menos para cierta prensa, aunque los cursos de italiano y alemán tuvieron una vida algo más larga.

\subsection{El método de Ahn como parodia}

Llegamos al final de nuestra investigación con una serie de textos periodísticos muy singulares. En ellos se acuña la expresión 'método de Ahn' para indicar que algo o alguien es cómico, incongruente o inservible. Se usa con sarcasmo, para ridiculizar algo o a alguien. A veces, la expresión va acompañada de algún ejemplo extraído del mismo manual de Ahn como ocurre en el primer extracto encontrado en La Época (ejemplar número 15.933 del 28 de septiembre de 1894). Se trata de una noticia, no firmada, sobre reformas de enseñanza $\mathrm{y}$, en concreto, del cambio de asignaturas. Uno de estos cambios, el diario lo considera 'á todas luces cómico, y recuerda aquellas preguntas y respuestas del método de Ahn : 'Tiene usted un cortaplumas ?- No, pero tengo un par de botas'

El resto de alusiones cómicas al método de Ahn en la prensa histórica aparecen en el siglo XX, y particularmente, entre 1909 y 1932. La primera de ellas apareció en El Orden un 13 de marzo de 1909. En la página tres una noticia llamada Dimes y Diretes alude al método de Ahn para criticar a otra publicación llamada La Iberia. No reproducimos la noticia entera por su extensión pero sí los tres primeros párrafos para captar mejor la irónica alusión al método de Ahn :

¿Conocen Vs. El método de Ahn precioso libro para aprender francés? Pues los temas allí escritos son una palmaria muestra de lo que á nosotros nos ocurre con "La Iberia".

¿Ha visto V. mi sombrrero ? Dice uno de los temas del citado libro.- No señor aquí tengo su paraguas-.

Es decir, que la mayor incongruencia se observa, entre las preguntas y respuestas.

Unos años más tarde aparece otra alusión cómica al método de Ahn en el diario satírico y humorístico Buen Humor (el 7 de enero de 1923) en una historia sobre préstamos. Hacia el final de la historia leemos :

En diferentes ocasiones me han preguntado algunas dichosas personas si es posible empeñar una cosa tan íntima como la anteriormente nombrada.

82 ¡Que si es posible !...No es difícil oir en cualquier calle a dos individuos que se encuentran de improviso lo siguiente, digno del método de Ahn: -¡Hola, querido! ¿Tienes ahí diez reales ?- No ; pero tengo cinco camisetas.

83 Y esa respuesta no es más ni menos que la salvación. ¿Comprenden ustedes ?...

Dos años después, en la portada del diario de información gráfica y literaria Región (15 de abril de 1925) aparece una noticia titulada Un juramento comunista dentro de la sección llamada De aquí y de alla. De nuevo, el método de Ahn sale a la palestra, esta vez como una 'adorable incongruencia' :

Si la renovación del mundo ha de ser efectuada por comunistas como el señor RaffinDugens, diputado francés, el mundo quedará como está. Todo lo más que lograrán los renovadores será ponerle una máscara. 

entre 1860 y 1900. En ese período, el Curso de francés alcanzó treinta y seis ediciones mientras que el Curso de inglés se reeditó veinte veces, convirtiéndose ambos en los manuales más (re)editados en el siglo XIX español para aprender francés e inglés respectivamente. Además, los resultados de la prensa histórica referidos a ese período ascienden al ochenta por ciento del global obtenido. Todo lo cual nos lleva a concluir que el innovador método de Ahn fue el más dominante, por encima del de Ollendorff, durante las últimas cuatro décadas del siglo XIX español. plaza de honor. La hora de los manuales de Ahn llegaba a su fin como herramienta pedagógica y didáctica. La aparición de nuevos métodos innovadores como los de Berlitz, Gouin, Gaspey-Otto-Sauer, Luigi Pavia, entre otros, empezaron a copar el mercado editorial español relegando el método de Ahn al baúl de los recuerdos hacia finales de la primera mitad del siglo XX. 
Apéndice

Muestra de algunos de los adaptadores del método de Ahn en Europa y América, con especial atención a España :

\begin{tabular}{|c|c|c|c|}
\hline Adaptador & Título & Año & País y editor \\
\hline $\begin{array}{l}\text { Giuseppe } \\
\text { Marchetti }\end{array}$ & $\begin{array}{l}\text { A new... method of learning the Italian language, after } \\
\text { the system of Franz Ahn }\end{array}$ & 1852 & London, Franz Thimm \\
\hline $\begin{array}{l}\text { Francisco de } \\
\text { Lencastre }\end{array}$ & $\begin{array}{l}\text { Nouvelle méthode pratique et facile pour apprendre la } \\
\text { langue portugaise, composé d'après les principes de } \\
\text { Franz Ahn }\end{array}$ & 1883 & Leipzig, F. A. Brockhaus \\
\hline $\begin{array}{l}\text { José Carlos } \\
\text { Mariani }\end{array}$ & $\begin{array}{l}\text { Methodo de Ahn para aprender facilmente a } \\
\text { linguaAllemã vertido do Francez. }\end{array}$ & 1876 & $\begin{array}{l}\text { Rio de Janeiro, } \\
\text { Laemmert }\end{array}$ \\
\hline J.J.B. Poclet & $\begin{array}{l}\text { DrAhn's first french course: being a new, practical, } \\
\text { and easy method of learning the French language }\end{array}$ & 1877 & London, T.J. Allman \\
\hline $\begin{array}{l}\text { Michal } \\
\text { Amszejewicz }\end{array}$ & $\begin{array}{l}\text { Ahn'apraktyczneprawidlanauczeniasiĘ } \\
\text { krótkimczasiejĘzykaruskieg }\end{array}$ & 1887 & $\begin{array}{l}\text { Warszawa, Jana } \\
\text { Breslauera }\end{array}$ \\
\hline $\begin{array}{l}\text { Stéphane } \\
\text { Barlet }\end{array}$ & Dr Ahn's first French course & 1876 & London, W. Tegg\& Co \\
\hline $\begin{array}{l}\text { Heinrich } \\
\text { Wofgang Just }\end{array}$ & $\begin{array}{l}\text { A german grammar: a companion to Dr Ahn's German } \\
\text { method }\end{array}$ & 1869 & $\begin{array}{l}\text { Boston, Sever, Francis \& } \\
\text { Co }\end{array}$ \\
\hline I. Dallos & $\begin{array}{l}\text { Praktischer Lehrgang zur schnellen und leichten } \\
\text { Erlennung der ungarischen Sprache: nach der F. } \\
\text { Ahn's Lernmethode }\end{array}$ & $1880 ?$ & $\begin{array}{l}\text { Budapest, } \quad \text { Robert } \\
\text { Lampel }\end{array}$ \\
\hline $\begin{array}{l}\text { Carl Theodor } \\
\text { Eben }\end{array}$ & $\begin{array}{l}\text { Ahn's Lehrgang der Englischen Sprache für Deutsche } \\
\text { in Amerika }\end{array}$ & 1891 & $\begin{array}{l}\text { Philadelphia, Kohler } \\
\text { Publishing Co }\end{array}$ \\
\hline $\begin{array}{l}\text { Giuseppe } \\
\text { Arnaud }\end{array}$ & $\begin{array}{l}\text { Nuovo metodo pratico-teorico per imparare la lengua } \\
\text { inglese: secondo il sistema di F. Ahn }\end{array}$ & 1869 & Milano, Gnocchi \\
\hline Enrico Wild & $\begin{array}{l}\text { Nuovo metodo pratico e facile per imparare la lingua } \\
\text { tedesca : proposto alla gioventù del DrF. Ahn }\end{array}$ & 1896 & Leipzig, Brockhaus \\
\hline P. Condigiorgi & $\begin{array}{l}\text { Ahn's new practical and easy German method applied } \\
\text { on the English language }\end{array}$ & 1871 & $\begin{array}{l}\text { Constantinople, } \\
\text { Christian Roth }\end{array}$ \\
\hline P. Henn & Ahn's first French reader; with notes and vocabulary & 1875 & New York, E. Steiger \\
\hline $\begin{array}{l}\text { Henrique } \\
\text { Brunswick }\end{array}$ & Methodo de Ahn. Curso de linguahespanhola & 1888 & Porto, E. Chardron \\
\hline $\begin{array}{ll}\text { Henry } & \text { Mac } \\
\text { Veigh } & \end{array}$ & $\begin{array}{l}\text { Método de Ahn. Primer curso de francés, arreglado al } \\
\text { castellano por el Profesor H. Mac-Veigh }\end{array}$ & 1857 & $\begin{array}{l}\text { Madrid, G. Hernández y } \\
\text { Artés }\end{array}$ \\
\hline
\end{tabular}




\begin{tabular}{|l|l|l|l|}
\hline $\begin{array}{l}\text { Henry Mac } \\
\text { Veigh }\end{array}$ & $\begin{array}{l}\text { Método de Ahn. Segundo curso de francés arreglado al } \\
\text { castellano y revisado por H. Mac-Veigh }\end{array}$ & 1858 & $\begin{array}{l}\text { Madrid, Librería Durán, } \\
\text { Imprenta de A. Gómez } \\
\text { Fuentenebro }\end{array}$ \\
\hline $\begin{array}{l}\text { Henry Mac } \\
\text { Veigh }\end{array}$ & $\begin{array}{l}\text { Método de Ahn. Curso de inglés, arreglado al } \\
\text { castellano por el Profesor H. Mac-Veigh }\end{array}$ & 1859 & $\begin{array}{l}\text { Madrid, Librería Durán, } \\
\text { Imprenta de A. Gómez } \\
\text { Fuentenebro }\end{array}$ \\
\hline $\begin{array}{l}\text { Francisco } \\
\text { María Rivero }\end{array}$ & Método de Ahn. Primero y segundo curso de italiano & 1873 & Madrid, Bailly-Baillière \\
\hline Camilo Vallés & $\begin{array}{l}\text { Nuevo método para aprender alemán según el sistema } \\
\text { de Franz Ahn. Primer curso }\end{array}$ & 1873 & Madrid, Bailly-Baillière \\
\hline Camilo Vallés & $\begin{array}{l}\text { Nuevo método para aprender alemán según el sistema } \\
\text { de Franz Ahn. Segundo y tercer curso }\end{array}$ & 1875 & Madrid, Bailly-Baillière \\
\hline Paula Hidalgo & $\begin{array}{l}\text { Método de Ahn. Primero y segundo curso de portugués } \\
\text { con la clave de temas }\end{array}$ & 1876 & Madrid, Bailly-Baillière \\
\hline
\end{tabular}

\section{BIBLIOGRAFÍA}

\section{Fuentes primarias $^{1}$}

Anuario del comercio, de la industria, de la magistratura y de la administración.

Buen Humor.

El Clamor Público.

El Correo Militar.

La Correspondencia de España.

Diario de Córdoba.

Diario Oficial de Avisos de Madrid.

La Discusión.

El Eco Toledano.

La Época.

La España.

La Esperanza.

El Heraldo de Madrid. 
La Iberia.

La Igualdad.

El Imparcial.

El Orden.

El Pensamiento Español.

La Regeneración.

Región.

Revista Contemporánea.

El Sol.

La Unión Ilustrada.

\section{Fuentes secundarias}

FISCHER, Denise, GARCÍA BASCUÑANA, Juan F. \& GÓMEZ, María Trinidad (2004). Repertorio de gramáticas y manuales para la enseñanza del francés en España (1565-1940). Barcelona : PPU.

HAMMAR, Elisabeth (1993). « Des méthodes Ahn/Ploetz aux méthodes directes. Pratiques

d'enseignement des langues en Suède de 1850 à 1905 ». Documents pour l'histoire du français langue étrangère ou seconde, 12, 11-15.

HERBERT, Christ (1993). « De Meidinger à Ploetz en passant par Seidenstücker, Ahn, et Ollendorff, ou le cheminement de la méthodologie synthétique ». Documents pour l'histoire du français langue

étrangère ou seconde, 12, 5-10.

RIUS DALMAU, María Inmaculada (2010). Aprender francés en España entre 1876 y 1939. Barcelona: PPU.

WILLEMS, Aline (2013). « Französischlehrwerke im Deutschland des 19. Jahrhunderts ».

Romanische Sprachen und ihre Didaktik, Band 46. Stuttgart: ibidem-Verlag.

LOMBARDERO CAPARRÓs, Alberto (2015). The historiography of English Language Teaching in Spain: A

Corpus of Grammars and Dictionaries (1769-1900). Tesis Doctoral, Universitat Rovira i Virgili. (308 p.).

Em ligne : http://hdl.handle.net/10803/318808

PONCE DE LEÓN ROME, Rogelio (2009). « Los inicios de la enseñanza-aprendizaje del portugués en España : breves consideraciones sobre el Primero y segundo curso de portugués (Madrid 1876)». Documents pour l'histoire du français langue étrangère ou seconde. 42 | 2009 [Maria Eugenia Fernandez Fraile et Javier Suso López (dir.). Approches contrastives et multilinguisme dans l'enseignement des langues en Europe (XVI $I^{e} X X^{e}$ siècles)]. En ligne : http://dhfles.revues.org/154 (06 mai 2016).

\section{NOTAS}

1. Todos los extractos de prensa incluidos en esta sección se reproducen en su original manteniendo la ortografía del castellano de la época que no difiere mucho de la actual y que, por lo tanto, no supondrá ninguna traba para su comprensión.

2. Hemeroteca Digital de la Biblioteca Nacional de España (HDBNE) y la Biblioteca Virtual del Patrimonio Histórico (BVPH).

3. Negrita en su original. 
1. Con el fin de no sobrecargar la bibliografía, se han excluido las obras que ya aparecen completamente referenciadas en el texto y en el apéndice 1. Respecto a la prensa histórica incluimos sólo el título del periódico o revista.

\section{RESÚMENES}

El presente estudio tiene como objetivo principal analizar la verdadera influencia del innovador método de Ahn en España durante la segunda mitad del siglo XIX y principios del siglo XX. Para ello hemos consultado los dos repertorios digitales de prensa histórica más significativos a nivel español : la Hemeroteca Digital de la Biblioteca Nacional de España (en adelante, HDBNE) y la Biblioteca Virtual de Prensa Histórica (en adelante, BVPH) del Ministerio de Educación, Cultura y Deportes. El 'método de Ahn' ha sido ampliamente estudiado por la historiografía de la didáctica de lenguas segundas o extranjeras (cf. Herbert 1993; Hammar 1993 ; Rius 2010 y Willems 2013, entre otros). No obstante, poco o nada se sabe de su influencia socio-cultural en una determinada tradición nacional. Para llenar parcialmente esa laguna, nos centramos en la tradición española y recurrimos a la prensa histórica de la época para calibrar la influencia del método de Ahn en su verdadero contexto histórico, social y cultural.

This article aims at gauging the real influence exerted by the innovative 'Ahn's method' in Spain throughout the second half of the XIX century and the first decades of the XX by a thorough perusal of two of the most significant online repositories of historical press in Spain: the Hemeroteca Digital de la Biblioteca Nacional de España (henceforth, HDBNE) and the Biblioteca Virtual de PrensaHistórica (henceforth, BVPH) from the Ministry of Education, Culture and Sports. Ahn'sactual method of teaching and learning languages has been widely studied by the historiography of second or foreign language teaching and learning ( $c f$. Herbert 1993; Hammar 1993; Rius 2010; Willems 2013, among others). However, there is no background research into its socio-cultural influenceon a specific national tradition. To partly fill this gap, this study focuses on the Spanish tradition and on the press of the time so as to reconstruct the influence of Ahn's method in its due social, historical and cultural context.

\section{ÍNDICE}

Palabras claves: Franz Ahn, método de Ahn, prensa histórica, España, siglos XIX y XX

Keywords: Franz Ahn, Ahn's method, historical press, Spain, 19th and 20th centuries

\section{AUTOR}

\section{ALBERTO LOMBARDERO CAPARRÓS}

Centro de Estudios Superiores Alberta Giménez (CESAG). Palma de Mallorca (Espagne) 